\title{
THE EFFECT OF CONCENTRATION, THERMAL HISTORY AND CELL SEEDING DENSITY ON THE INITIAL MECHANICAL PROPERTIES OF AGAROSE HYDROGELS
}

Conor T. Buckley ${ }^{1,3}$, Stephen D. Thorpe ${ }^{1,3}$, Fergal J. O’Brien ${ }^{1,2}$, Anthony J. Robinson ${ }^{3}$ and Daniel J. Kelly ${ }^{1.3,}$.

1. Trinity Centre for Bioengineering, School of Engineering, Trinity College Dublin, Ireland.

2. Dept. of Anatomy, Royal College of Surgeons in Ireland, Dublin, Ireland.

3. Dept. of Mechanical and Manufacturing Engineering, School of Engineering, Trinity College Dublin, Ireland.

*Corresponding author

E-mail address: kellyd9@tcd.ie

Address: Trinity Centre for Bioengineering

School of Engineering

Trinity College Dublin

Ireland

Telephone: +353-1-896-3947

Fax: $+353-1-679-5554$

Keywords: Agarose, hydrogel, mechanobiology, cell seeding density, cartilage tissue engineering. 


\begin{abstract}
Agarose hydrogels are commonly used for cartilage tissue engineering studies and to provide a three dimensional environment to investigate cellular mechanobiology. Interpreting the results of such studies requires accurate quantification of the mechanical properties of the hydrogel. There is significant variation in the reported mechanical properties of agarose hydrogels, and little is reported on the influence of factors associated with mixing these hydrogels with cell suspensions on their initial mechanical properties. The objective of this study was to determine the influence of agarose concentration, the cooling rate during gelation, the thermal history following gelation and the cell seeding density on the initial mechanical properties of agarose hydrogels. The average ramp modulus of $2 \%$ agarose gel in tension was $24.9 \mathrm{kPa}( \pm 1.7, \mathrm{n}=10)$, compared with $55.6 \mathrm{kPa}( \pm 0.5, \mathrm{n}=10)$ in compression. The average tensile equilibrium modulus was $39.7 \mathrm{kPa}( \pm 5.7, \mathrm{n}=6)$, significantly higher than the compressive equilibrium modulus of $14.2 \mathrm{kPa}( \pm 1.6, \mathrm{n}=10)$. The equilibrium and dynamic compressive modulus of agarose hydrogels were observed to reduce if maintained at $37^{\circ} \mathrm{C}$ following gelation compared to samples maintained at room temperature. Depending on the methodology used to encapsulate chondrocytes within agarose hydrogels, the equilibrium compressive modulus was found to be significantly higher for acellular $2 \%$ agarose gels compared to $2 \%$ agarose gels seeded at approximately $40 \times 10^{6}$ cells $/ \mathrm{mL}$. These results have important implications for interpreting the results of chondrocyte mechanobiology studies in agarose hydrogels.
\end{abstract}




\section{INTRODUCTION}

Tissue engineering has demonstrated significant potential for cartilage defect repair and could ultimately reduce the need for tissue transplants and prosthetic implants. Hydrogels are a class of scaffold that are commonly used in cartilage tissue engineering and include alginate, agarose, poly(ethylene glycol) (PEG), poly(vinyl alcohol) (PVA), pluronics, chitosan, collagen and fibrin as examples (Lum and Elisseeff 2003; Elisseeff et al. 2005). A significant benefit of hydrogels is their potential use as an in situ forming scaffold for cartilage defect repair. In addition, their swelling nature provide an aqueous environment comparable to soft tissue for encapsulated cells and their high water content facilitates the exchange of nutrients and gases (Lum and Elisseeff 2003). Agarose, a linear polysaccharide extracted from marine red algae, is a thermosetting hydrogel that undergoes gelation in response to a reduction in temperature. Chondrocytes cultured in agarose will maintain their phenotype and synthesize near normal levels of collagen II and proteoglycan (Benya and Shaffer 1982; Aydelotte and Kuettner 1988; Aulthouse et al. 1989). Over time, chondrocyte seeded agarose hydrogels have been shown to produce a functional extracellular matrix in free swelling culture (Buschmann et al. 1992). For these and other reasons, numerous investigators have utilised agarose hydrogels for cartilage tissue engineering applications specifically to assess the elaboration of pericellular (Quinn et al. 2002) and extracellular matrix (Miyata et al. 2004; Miyata et al. 2005; Mouw et al. 2005), chondrogenesis of mesenchymal stem cells (Awad et al. 2004; Mauck et al. 2006), the interaction of biochemical stimulants (Coleman et al. 2007; Ng et al. 2007) and as a scaffold material in animal models of cartilage defect repair (Rahfoth et al. 1998; Weisser et al. 2001). 
Agarose is also commonly used to provide a three dimensional environment to investigate chondrocyte mechanotransduction pathways in vitro. Typically such studies involve encapsulating cells within agarose and subjecting the cell-seeded hydrogel to defined levels of mechanical deformation or loading and observing the resulting changes in cellular structure and organisation (Freeman et al. 1994; Knight et al. 1998; Lee et al. 2000; Sawae et al. 2004). The mechanobiology of chondrocytes and chondrocyte progenitor cells is also commonly investigated using the agarose model. The application of appropriate levels of dynamic compressive loading (Buschmann et al. 1995; Lee and Bader 1997; Lee et al. 1998; Lee et al. 2000; Mauck et al. 2000; Chowdhury et al. 2001; Mauck et al. 2002; Mauck et al. 2003; Mauck et al. 2003; Kelly et al. 2004; Ng et al. 2006) or hydrostatic pressure (Toyoda et al. 2002; Toyoda et al. 2003) to chondrocytes encapsulated in agarose hydrogels has also been shown to enhance their biosynthetic activity. Agarose hydrogels have also been used in perfusion (Xu et al. 2006) and rotating-wall bioreactor systems (Hu and Athanasiou 2005). Furthermore the role of mechanical loading in regulating chondrogenesis of progenitor cells is commonly investigated using the agarose hydrogel culture system (Walker et al. 2000; Elder et al. 2001; Huang et al. 2004; Finger et al. 2007; Mauck et al. 2007; Thorpe et al. 2008). In many of these studies, computational techniques such as the finite element method are used to determine spatial variations in the local mechanical environment within the agarose hydrogel due to the applied levels of loading (Freeman et al. 1994; Hunter and Levenston 2002; Mauck et al. 2003; Huang et al. 2004; Lima et al. 2004; $\mathrm{Ng}$ et al. 2006). 
The intrinsic mechanical properties of agarose hydrogels have been shown to depend on their concentration. However there is significant variation in the reported values for the compressive properties of agarose gel at any given concentration (Buschmann et al. 1992; Mauck et al. 2000; Normand et al. 2000; Gu et al. 2003; de Freitas et al. 2006; Likhitpanichkul et al. 2006). Complete and concise characterisation of the mechanical properties of these hydrogels at different concentrations is necessary to facilitate their use as a scaffold material in cartilage tissue engineering. Perhaps more importantly, characterising the mechanical properties of these gels is also necessary to properly interpret the results of cellular mechanotransdution studies that utilise these gels. While factors associated with material testing protocols and differences in molecule weight, gel preparation and storage conditions may be responsible for much of the reported differences (Normand et al. 2000; de Freitas et al. 2006), little is reported on the influence of factors associated with mixing these hydrogels with cell suspensions on their initial mechanical properties. Depending on the concentration of the agarose and the subsequent stiffness of the hydrogel, the addition of cells into the gel matrix could significantly alter their mechanical properties. The objective of this study was to determine the influence of agarose concentration, the cooling rate during gelation, the thermal history following gelation and the cell seeding density on the initial mechanical properties of agarose hydrogels. 


\section{METHODS}

Fabrication of acellular agarose gels

Acellular agarose solution (Type VII, Sigma) was prepared by mixing agarose powder with phosphate buffered saline (PBS) and autoclaving at $121^{\circ} \mathrm{C}$ to obtain final gel concentrations of $2 \%, 3 \%, 4 \%$ and $6 \%(\mathrm{w} / \mathrm{v})$. The agarose gel was cast in a stainless steel mould to produce construct cylinders $(\varnothing 6 \times 4 \mathrm{~mm})$. A single batch of agarose was used for each study described.

To ascertain the effect of testing temperature on the overall mechanical properties, three testing regimes were assessed as follows. Acellular agarose hydrogels $(2 \%, 4 \%$ and $6 \%)$ were prepared, allowed to cool to room temperature ( $\sim 30 \mathrm{mins})$ and separated into three experimental groups as follows; (i) gels maintained overnight at room temperature and tested at room temperature (ii) gels maintained overnight at $37^{\circ} \mathrm{C}$, allowed to cool for 60 minutes prior to testing at room temperature (iii) gels maintained overnight at $37^{\circ} \mathrm{C}$ and tested at $37^{\circ} \mathrm{C}$.

Batch to batch variation was assessed by fabricating five separate groups of $2 \%$ agarose hydrogels (maintained overnight at room temperature) and performing mechanical tests at room temperature.

Acellular constructs were also fabricated to investigate the influence of the cooling rate during gelation on the resulting mechanical properties. Agarose gel was prepared at a final concentration of $4 \%$ and cast in copper moulds. Thermocouples were employed and 
mounted in one of the wells to monitor the change in temperature with time. Two cooling rates, a rapid cooling rate and a slow cooling rate were employed (see Fig. 1). For both cooling protocols the agarose was first cooled at the same rate to $37^{\circ} \mathrm{C}$, to mimic the situation where the gel is not mixed with the cells until this temperature is reached. For rapid cooling experiments, the mould was placed on an ice bath. For slow cooling, gelation occurred as the agarose cooled to room temperature. For all other experiments, gelation was achieved using the slow cooling protocol. Mechanical tests were performed at room temperature unless otherwise stated.

\section{Fabrication of chondrocyte encapsulated agarose gels}

Full-depth slices of cartilage were harvested under aseptic conditions from the femoral condyles of four month old porcine donor animals $(\sim 50 \mathrm{~kg}, \mathrm{n}=3)$, and rinsed thoroughly with PBS containing penicillin/streptomycin $(200 \mathrm{U} / \mathrm{ml})$. Chondrocytes were isolated from cartilage slices through incubation with DMEM/F12 containing collagenase type II $(0.5 \mathrm{mg} / \mathrm{ml})$ (all from Sigma-Aldrich, Dublin, Ireland) for 18 hours under constant rotation at $37^{\circ} \mathrm{C}$. The cell suspension was passed through a $40 \mu \mathrm{m}$ pore-size cell sieve (BD Falcon, Unitech, Ireland) and the filtrate centrifuged and rinsed with PBS twice. Cells were seeded at a density of 50,000 cells $/ \mathrm{cm}^{2}$ in $175 \mathrm{~cm}^{2} \mathrm{~T}$ - flasks and expanded (1:2 ratio) to passage one $(\mathrm{P} 1)$. Cell number and viability were determined using a haemacytometer and 0.4\% trypan blue staining. Isolated chondrocytes from all joints were pooled and maintained in DMEM/F-12 (Sigma-Aldrich, Dublin, Ireland) supplemented with $10 \% \mathrm{v} / \mathrm{v}$ fetal bovine serum (FBS) and 100U/ml 
penicillin/streptomycin (GIBCO, Biosciences, Dublin, Ireland) during the expansion phase.

Porcine chondrocytes (P1) were suspended in DMEM/F12 and mixed with 4\% molten agarose (Type VII, Sigma-Aldrich, Dublin, Ireland) at approximately $40^{\circ} \mathrm{C}$, and then allowed to cool at room temperature until gelation had occurred ( 30 minutes). Constructs with two different cell densities were produced, $10 \times 10^{6}$ and $40 \times 10^{6}$ cells $/ \mathrm{mL}$. Two cell encapsulation methodologies were adopted: A and B.

Cellular agarose hydrogels were fabricated by mixing a cell suspension with $4 \%$ agarose. For method A, the cell suspension was produced by adding DMEM/F12 to the cell pellet to obtain a final volume for the cell suspension equal to that of the molten agarose. Sufficient DMEM/F12 was initially added to the cell pellet to produce a cell suspension of $80 \times 10^{6}$ or $20 \times 10^{6}$ cells $/ \mathrm{mL}$ of medium, providing a cell-gel suspension of exactly $40 \times 10^{6}$ or $10 \times 10^{6}$ cells $/ \mathrm{mL}$ after mixing with the agarose. For method $\mathrm{B}$, a volume of DMEM/F12 equal to that of the molten agarose was initially added to the cell pellet, to produce an exact final agarose gel concentration of $2 \%$. In this case, a known volume of DMEM/F12 was added to the cell pellet to give a cell suspension of either $80 \times 10^{6}$ or $20 \times 10^{6}$ cells for every $1 \mathrm{~mL}$ of medium. This was then added to a volume of $4 \%$ agarose equal to the volume of medium added to the cell pellet. The agarose/cell suspension was cast in a stainless steel mould to produce cylindrical constructs $(\varnothing 6 \mathrm{x} 4 \mathrm{~mm})$. Chondrocyte laden hydrogels were incubated overnight at $37^{\circ} \mathrm{C}$. Mechanical tests were performed after gels were allowed to equilibriate for $60 \mathrm{mins}$ at room temperature. 


\section{Mechanical testing}

Both acellular and chondrocyte-laden constructs were mechanically tested in unconfined compression using a standard materials testing machine with a $5 \mathrm{~N}$ load cell (Zwick Z005, Roell, Germany). All tests were performed in a phosphate buffered saline (PBS) bath the temperature of which was controlled utilising silicone heating pads and a PID (proportional-integral-derivative) controller. A preload of $0.01 \mathrm{~N}$ was applied to ensure that the surfaces of the gel constructs were in direct contact with the impermeable loading platens and to ascertain the height of the specimens. Stress-relaxation tests were performed, consisting of a ramp and hold cycle with a ramp displacement of $0.001 \mathrm{~mm} / \mathrm{s}$ until 10\% strain was obtained; this was maintained until equilibrium was reached $(\sim 30-40$ minutes). The compressive equilibrium modulus was calculated by taking the stress determined at complete force relaxation and dividing by the applied strain. Dynamic tests were performed immediately after the stress-relaxation cycle. The strain was maintained at $10 \%$ and a cyclic strain of $1 \%$ was applied for 10 cycles. Three such tests were performed at frequencies of $0.1 \mathrm{~Hz}, 1 \mathrm{~Hz}$, and $5 \mathrm{~Hz}$ where indicated. Dynamic moduli at each frequency were calculated through the ratio of the determined stress amplitude to the applied strain amplitude.

To assess the linearity of the acellular material $(2 \% \mathrm{w} / \mathrm{v}$ agarose concentration), successive ramp-and-hold tests were performed in both tension and compression. For the compressive case, samples were tested in unconfined compression in a series of ten steps of $2 \%$ strain up to a final of $20 \%$ total strain. At each step, the strain was applied at a rate 
of $0.001 \mathrm{~mm} / \mathrm{s}$ and then held constant for 40 minutes to allow relaxation of the specimen (see Fig. 2). The equilibrium modulus was calculated for each strain increment.

To determine the tensile properties of the material $(2 \% \mathrm{w} / \mathrm{v}$ agarose concentration), samples were secured in custom grips with sandpaper and tested in uniaxial tension. Sample dimensions were taken as the mould dimensions and the gauge length was noted after application of the pre-load. For the tensile tests, samples were again strained in steps of $2 \%$ to failure. The strain rate was $0.001 \mathrm{~mm} / \mathrm{s}$ and the strain was held constant for 5 minutes at each increment (relaxation was observed to occur faster during tensile testing). The equilibrium modulus was calculated for each strain increment. The ramp modulus in tension and compression was assessed by straining samples at a rate of $0.5 \% / \mathrm{s}$ until failure occurred. The moduli were calculated from the slope of a linear fit to the stressstrain data. Ultimate strain was calculated as the strain at failure.

\section{Statistical Analysis}

Numerical and graphical results are reported in the form of mean \pm standard error from the mean (SE). All statistical analyses were performed using GraphPad Prism (Version 4.3) software. Both one- and two- way ANOVA with Tukey post-testing were used.

\section{RESULTS}

\section{Tension-Compression linearity}

$2 \%$ agarose gel displayed linear stress-strain behaviour when stretched in tension at 0.5 $\% / \mathrm{sec}$ to failure (see Fig. 3a), with an average ramp modulus of $24.9 \mathrm{kPa}( \pm 1.7, \mathrm{n}=10)$. 
The average ultimate tensile strain (defined as the strain at the ultimate tensile stress) was $17.9 \%( \pm 0.9, \mathrm{n}=10)$. Agarose gel appeared stiffer in compression, with an average ramp modulus of $55.6 \mathrm{kPa}( \pm 0.5, \mathrm{n}=10)$. The material response is less linear, with a certain amount of stress stiffening observed when compressed at $0.5 \% / \mathrm{sec}$ to failure (see Fig. 3a). The average ultimate compressive strain was $31.7 \%( \pm 0.4, n=10)$. The equilibrium modulus was determined by applying a series of ramp and hold displacements in both tension and compression, allowing force readings to reach equilibrium between each ramp and hold. The equilibrium stress-strain curve was also non-linear (see Fig. 3b), but did display linear behaviour in both tension and compression at intermediate strain values. The average tensile equilibrium modulus was $39.7 \mathrm{kPa}( \pm 5.7, \mathrm{n}=6)$, significantly higher than the average compressive equilibrium modulus of $14.2 \mathrm{kPa}( \pm 1.6, \mathrm{n}=10)$.

\section{Gel concentration}

The equilibrium modulus was observed to increase with increasing gel concentration, reaching an average value of $95.1 \mathrm{kPa}( \pm 2.1, \mathrm{n}=3)$ at $6 \%$ concentration for samples maintained and tested at room temperature (see Fig. 4). The dynamic modulus was also observed to increase with increasing gel concentration, from a value of $45.1 \mathrm{kPa}( \pm 0.4$, $\mathrm{n}=3)$ for $1 \mathrm{~Hz}$ at $2 \%$ concentration, to $227.3 \mathrm{kPa}( \pm 2.2, \mathrm{n}=3)$ at $6 \%$ concentration. No statistically significant difference was observed between the dynamic modulus at $0.1 \mathrm{~Hz}$, $1 \mathrm{~Hz}$ or $5 \mathrm{~Hz}$ for each gel concentration, but all measures were statistically different when compared to other gel concentrations $(\mathrm{p}<0.001)$. Gels maintained at $37^{\circ} \mathrm{C}$ overnight following gelation and mechanically tested at $37^{\circ} \mathrm{C}$, demonstrated significantly lower equilibrium and dynamic moduli to corresponding gels maintained and tested at room 
temperature for all gel concentrations. A partial or in some cases total recovery in the mechanical properties were observed if gels that had been maintained at $37^{\circ} \mathrm{C}$ were allowed to cool to room temperature for $60 \mathrm{mins}$ prior to testing.

\section{Gel cooling rate}

There was no statistical difference between the compressive equilibrium modulus of agarose hydrogel that underwent gelation at a rapid $(56.7 \pm 5.9 \mathrm{kPa}, \mathrm{n}=3)$ or slow $(53.2 \pm$ $1.7 \mathrm{kPa}, \mathrm{n}=5$ ) cooling rate.

\section{Cell seeding density}

Two separate cell encapsulation methodologies were used to fabricate cell seeded agarose hydrogels (see methods section). For method A (which yields an exact cell seeding concentration), no significant difference was observed between the equilibrium modulus for acellular and cellular gels at both seeding concentrations (Fig. 5a). A small but significant drop was observed in the cellular constructs for the $1 \mathrm{~Hz}$ dynamic modulus (Fig. $5 \mathrm{~b}, \mathrm{p}<0.05$ for $10 \times 10^{6}$ cells $/ \mathrm{mL}, \mathrm{p}<0.001$ for $40 \times 10^{6}$ cells $/ \mathrm{mL}$ ); however there was no difference between the dynamic modulus at 10 or $40 \times 10^{6}$ cells $/ \mathrm{ml}$. For method B (which yields an exact gel concentration of $2 \%)$, both the equilibrium modulus $(9.5 \pm 0.3$ $\mathrm{kPa}, \mathrm{p}<0.05)$ and the dynamic modulus $(30.9 \pm 0.4 \mathrm{kPa}, \mathrm{p}<0.001)$ at $40 \times 10^{6}$ cells $/ \mathrm{mL}$ were lower than acellular constructs and cellular constructs fabricated using Method A. For gels fabricated using Method $\mathrm{B}$, the dynamic modulus at $40 \times 106$ cells $/ \mathrm{mL}$ was lower than that for $10 \times 10^{6}$ cells $/ \mathrm{mL}(\mathrm{p}=0.0003)$. 


\section{Batch-to-batch variability}

A degree of batch-to-batch variability was observed in both the equilibrium and dynamic modulus of $2 \%$ agarose gels tested at room temperature (see Fig. 6). For example the maximum equilibrium modulus obtained for batch $\mathrm{A}$ was found to be $16.4 \mathrm{kPa}( \pm 0.5$, $\mathrm{n}=3)$, compared to a minimum of $14.5 \mathrm{kPa}( \pm 0.4, \mathrm{n}=3)$ for batch $\mathrm{C}(\mathrm{p}<0.05)$. Similarly a maximum $1 \mathrm{~Hz}$ dynamic modulus of $45.5 \mathrm{kPa}( \pm 1.2, \mathrm{n}=3)$ was obtained for batch $\mathrm{A}$ compared to a minimum of $40.7 \mathrm{kPa}( \pm 1.7, \mathrm{n}=3)$ for batch $\mathrm{C}(\mathrm{p}<0.05)$.

\section{DISCUSSION}

Investigations of cellular mechanobiology and mechanotransduction pathways in three dimensional hydrogel cultures requires accurate quantification of the material behaviour of the hydrogel, and an understanding of how fabrication methodologies will regulate the behaviour of the gel. The objective of this paper was to first thoroughly investigate the mechanical properties of $2 \%$ agarose gel, which is a concentration commonly reported in the literature, and to then determine the influence of gel concentration, thermal history and the cell seeding density on the initial mechanical properties of the hydrogel. It was seen that these parameters influence the properties, but not all as initially expected.

Agarose gel displayed non-linear stress-strain behaviour. During ramp tension and compression tests, the gel appeared stiffer in compression than in tension. However, the results of the stress relaxation test (ramp and hold test) revealed that the equilibrium modulus was greater in tension than in compression. This apparent contradiction is attributed to the inherent differences between the constant strain-rate tests used to 
determine the ramp modulus, and the stress relaxation tests used to determine the equilibrium modulus. During ramp testing the load is borne by both fluid pressurisation and by deforming the solid phase of the hydrogel. The ramp modulus is therefore a useful measure of how the hydrogel might respond to physiological rates of loading; however its value is dependant on the rate of applied deformation. The equilibrium modulus is based on the equilibrium force reading at the end of each hold period during the stress relaxation test, at which point fluid no longer flows through the tissue and all the load is borne by the solid phase of the hydrogel. This measure is independent of the loading rate. The material behaviour in this respect can be considered similar to cartilage (Mow et al. 1980). The equilibrium modulus can be viewed as a measure of the inherent properties of the agarose hydrogel in the absence of fluid pressurisation within the gel. The greater equilibrium tensile values observed in the stress relaxation tests implies that the solid phase of agarose gel is inherently stiffer in tension than in compression. During equilibrium testing, significantly more stress relaxation is also observed in compression than in tension, which can be attributed in part to the significantly larger free surface area of the tensile samples compared to the compressive samples, which facilitates fluid flow. This may also explain why the ramp modulus in compression, as determined during constant strain-rate testing, is greater than that in tension as greater flow-generated stiffening (Akizuki et al. 1986) may occur in the thin cylindrical compression samples due to greater fluid pressurization compared to the tensile samples. Any increase in pore volume and hence increase in the gel permeability to fluid flow during ramp tensile testing would also contribute to this result. Friction at the platen during compression testing may also play a role in explaining the tension-compression differences. During the 
ramp phase of a compression test, any friction between the platen and the agarose gel will increase the force reading from the load cell, making the gel appear stiffer than it actually is.

The reported values for the unconfined compressive equilibrium modulus of $2 \%$ agarose gel from the literature can vary by an order of magnitude. A number of reasons for such variations have been proposed (de Freitas et al. 2006), including mechanical factors associated with material testing, differences in gel preparation and storage conditions, natural variations in the molecular weight of agarose and water absorption during storage among others. Gel concentration and molecular weight has also been shown to influence the tensile properties of agarose hydrogels (Normand et al. 2000), although less is known about the equilibrium tensile modulus. Many of the investigations involving cellular encapsulation utilise agarose type VII as was used in this work. As was observed from the batch to batch variation analysis, for $2 \%$ agarose hydrogels minimal variation was observed to occur in the overall mechanical properties ranging from an average batch maximum of $16.4 \mathrm{kPa}$ to a minimum of $14.5 \mathrm{kPa}$ for the compressive equilibrium modulus. It is believed that the use of an autoclave in gel fabrication is important in this regard. The testing procedures adopted in this work are similar to those reported by other researchers for testing of acellular and cell encapsulated hydrogels in unconfined compression (Mauck et al. 2000; Mauck et al. 2003; Kelly et al. 2006; Kelly et al. 2008). For example, Mauck et al. (2000) report an equilibrium Young's modulus of approximately $12 \mathrm{kPa}$ for the initial (day 0 ) mechanical properties of cellular $2 \%$ agarose hydrogels, similar to that observed in this study. Normand et al. (2000) report one of the 
few experiments investigating both the tensile and compressive properties of acellular agarose gels. They also observed significantly higher failure strains in compression than tension, albeit with higher stiffness values as observed in this study. A useful review on the available data for the mechanical properties of acellular agarose hydrogels is available in the literature (de Freitas et al. 2006). A critical parameter in determining the equilibrium modulus in unconfined compression of a biphasic material such as agarose is to allow sufficient time for the material to completely relax (which requires approximately $30 \mathrm{mins}$ ).

It was initially expected that the rate of cooling during gelation would influence the mechanical properties of agarose hydrogels. In all cases gels were first allowed to cool to approximately $37^{\circ} \mathrm{C}$, to mimic the procedure normally used for creating cellular encapsulated gels, since this is the temperature at which cells can be safely mixed with the hydrogel as cells are labile (subject to heat degradation) at higher temperatures. At this stage the gels were either cooled rapidly in an ice bath, or slowly at room temperature, to approximately $20^{\circ} \mathrm{C}$ (see Fig. 1). Despite the different cooling rates used in this study, it would appear that gelation occurred at similar temperatures in both cases, explaining the similar results observed for the two cooling rates. Slicing of cylindrical gels into thinner sections to examine if thermal gradients through the thickness of the gel might have led to changes in the stiffness also failed to reveal any differences (result not shown). Agarose hydrogels re-heated and then tested at $37^{\circ} \mathrm{C}$ following gelation at room temperature demonstrated significantly lower moduli than gels maintained at room temperature. This drop was partially (and in some cases totally) recovered if gels were 
tested at room temperature. Evidence for agarose possessing temperature dependant properties is available in the literature. It has been reported that fast gelation at temperatures below $35^{\circ} \mathrm{C}$ can result in the formation of a stiffer, more homogenous gel compared to gels cured at temperatures above $35^{\circ} \mathrm{C}$ (Aymard et al. 2001). That study found that the elastic modulus, as determined from ramp compression tests, varied with the curing temperature from 12 to $82 \mathrm{kPa}$, with the highest values obtained at curing temperatures between 5 and $15^{\circ} \mathrm{C}$. The authors suggested that this was due to modifications occurring in the gel network with changing temperature (i.e. dissociation of helix bundles, melting of helices), which is presumably also responsible for the temperature dependant properties observed in this study. Whether such low curing temperatures would negatively affect the viability of seeded cells needs to be further elucidated. Differences in stiffness values found in agarose gels formed in centrifuge tubes as apposed to stainless steel wells have also been attributed in part to faster cooling rates in stainless steel wells as they represent better heat sinks during cooling (de Freitas et al. 2006). Regardless of the cooling rate used, it is pertinent when testing cellular or acellular agarose gels to ensure that the thermal history (e.g. time following removal from incubator etc) of samples is identical in order to minimise variability in the measured mechanical properties and to allow for direct comparisons.

Cell-seeding of agarose hydrogels does influence the mechanical properties of the final construct, but again not as initially expected. For method A, an equal volume of cellsuspension and $4 \%$ agarose was mixed to yield a cell-gel mix of either $10 \times 10^{6}$ cells $/ \mathrm{mL}$ or $40 \times 10^{6}$ cells $/ \mathrm{mL}$; whereas for method $\mathrm{B}$, equal volumes of medium and gel were 
mixed, with the cells as extra volume above that of the mixture. For method B, the addition of $40 \times 10^{6}$ cells $/ \mathrm{mL}$ is observed to reduce the equilibrium modulus of the hydrogel, presumably by introducing greater porosity (of the order of $10 \mu \mathrm{m}$, the diameter of a chondrocyte) into a hydrogel with significantly lower pore sizes ( $\mathrm{Ng}$ et al. 2005). Given that the Young's modulus of a chondrocyte has been reported as approximately 0.6 $\mathrm{kPa}$ (Guilak et al. 1999), an order of magnitude lower than that of agarose, one might also have expected the equilibrium modulus of cell seeded agarose to decrease with increasing cell seeded density (and associated porosity) for method A. We hypothesise that this does not occur with method A because the effective concentration of the agarose actually increases with increasing cell seeding density, as the volume of culture media within the cell suspension that is mixed with the agarose will decrease as the volume of the cell suspension occupied by the cells increases. By always adding the same volume of culture media to the agarose with method $\mathrm{B}$, the concentration of the final hydrogel is maintained constant at each cell seeding density; however the total volume of the final mixture is increased each time by the volume of the cell pellet, thereby reducing the effective cell seeding density on a cells $/ \mathrm{ml}$ basis. In this case the reduction in modulus due to cell encapsulation is not offset by an increase in the effective concentration of the agarose. Therefore increasing the cell seeding density effectively lowers the initial mechanical properties of the cell seeded hydrogel using this encapsulation method. 


\section{CONCLUSION}

Altering the concentration of agarose gels had the most dramatic effect on their mechanical properties. Introducing sufficient cell density into the hydrogel can reduce the apparent mechanical properties of the construct, depending on the cell encapsulation method used. The local mechanical properties of the gel may actually increase with increasing cell density by indirectly increasing the gel concentration if this is not explicitly controlled for in the encapsulation methodology utilised. Agarose gels were also found to have temperature dependant mechanical properties following gelation. Even allowing for batch-to-batch variability in the mechanical properties of agarose hydrogels, it is still believed the general trends concerning the influence of cooling rate, concentration and cell seeding density found in this study are valid. Taken together, these results have important implications for interpreting the results of chondrocyte mechanobiology studies in agarose hydrogels, and for developing finite element models of such culture systems.

\section{ACKNOWLEDGEMENTS}

This work was funded by Enterprise Ireland (Proof-of-Concept: PC/ 2006/ 364) and Science Foundation Ireland (Research Frontiers Program: ENMF142). 


\section{REFERENCES}

Akizuki, S., Mow, V. C. and Muller, F., 1986. Tensile properties of human knee joint cartilage: I. Influence of ionic conditions, weight bearing, and fibrillation on the tensile modulus. Journal of Orthopaedic Research 4(4): 379-392.

Aulthouse, A. L., Beck, M., Griffey, E., Sanford, J., Arden, K., Machado, M. A. and Horton, W. A., 1989. Expression of the human chondrocyte phenotype in vitro. In Vitro Cellular \& Developmental Biology 25(7): 659-668.

Awad, H. A., Wickham, M. Q., Leddy, H. A., Gimble, J. M. and Guilak, F., 2004. Chondrogenic differentiation of adipose-derived adult stem cells in agarose, alginate, and gelatin scaffolds. Biomaterials 25(16): 3211-3222.

Aydelotte, M. B. and Kuettner, K. E., 1988. Differences between sub-populations of cultured bovine articular chondrocytes. I. Morphology and cartilage matrix production. Connective Tissue Research 18(3): 205-222.

Aymard, P., Martin, D. R., Plucknett, K., Foster, T. J., Clark, A. H. and Norton, I. T., 2001. Influence of thermal history on the structural and mechanical properties of agarose gels. Biopolymers 59(3): 131-144.

Benya, P. D. and Shaffer, J. D., 1982. Dedifferentiated chondrocytes reexpress the differentiated collagen phenotype when cultured in agarose gels. Cell 30(1): 215-224.

Buschmann, M. D., Gluzband, Y. A., Grodzinsky, A. J. and Hunziker, E. B., 1995. Mechanical compression modulates matrix biosynthesis in chondrocyte/agarose culture. Journal of Cell Science 108(4): 1497-1508.

Buschmann, M. D., Gluzband, Y. A., Grodzinsky, A. J., Kimura, J. H. and Hunziker, E. B., 1992. Chondrocytes in agarose culture synthesize a mechanically functional extracellular-matrix. Journal of Orthopaedic Research 10(6): 745-758.

Chowdhury, T. T., Bader, D. L. and Lee, D. A., 2001. Dynamic compression inhibits the synthesis of nitric oxide and PGE2 by IL-1 $\beta$-stimulated chondrocytes cultured in agarose constructs. Biochemical and Biophysical Research Communications 285(5): 1168-1174.

Coleman, R. M., Case, N. D. and Guldberg, R. E., 2007. Hydrogel effects on bone marrow stromal cell response to chondrogenic growth factors. Biomaterials 28(12): 207786.

de Freitas, P. S., Wirz, D., Stoiz, M., Gopfert, B., Friederich, N. F. and Daniels, A. U., 2006. Pulsatile dynamic stiffness of cartilage-like materials and use of agarose gels to validate mechanical methods and models. Journal of Biomedical Materials Research Part B-Applied Biomaterials 78B(2): 347-357. 
Elder, S. H., Goldstein, S. A., Kimura, J. H., Soslowsky, L. J. and Spengler, D. M., 2001. Chondrocyte differentiation is modulated by frequency and duration of cyclic compressive loading. Annals of Biomedical Engineering 29(6): 476-482.

Elisseeff, J., Puleo, C., Yang, F. and Sharma, B., 2005. Advances in skeletal tissue engineering with hydrogels. Orthodontics \& Craniofacial Research 8(3): 150-161.

Finger, A. R., Sargent, C. Y., Dulaney, K. O., Bernacki, S. H. and Loboa, E. G., 2007. Differential effects on messenger ribonucleic acid expression by bone marrow-derived human mesenchymal stem cells seeded in agarose constructs due to ramped and steady applications of cyclic hydrostatic pressure. Tissue Engineering 13(6): 1151-1158.

Freeman, P. M., Natarajan, R. N., Kimura, J. H. and Andriacchi, T. P., 1994. Chondrocyte cells respond mechanically to compressive loads. Journal of Orthopaedic Research 12(3): 311-320.

Gu, W. Y., Yao, H., Huang, C. Y. and Cheung, H. S., 2003. New insight into deformation-dependent hydraulic permeability of gels and cartilage, and dynamic behavior of agarose gels in confined compression. Journal of Biomechanics 36(4): 593598.

Guilak, F., Jones, W. R., Ting-Beall, H. P. and Lee, G. M., 1999. The deformation behavior and mechanical properties of chondrocytes in articular cartilage. Osteoarthritis and Cartilage 7(1): 59-70.

$\mathrm{Hu}$, J. C. and Athanasiou, K. A., 2005. Low-density cultures of bovine chondrocytes: Effects of scaffold material and culture system. Biomaterials 26(14): 2001-2012.

Huang, C. Y. C., Hagar, K. L., Frost, L. E., Sun, Y. and Cheung, H. S., 2004. Effects of cyclic compressive loading on chondrogenesis of rabbit bone-marrow derived mesenchymal stem cells. Stem Cells 22(3): 313-323.

Hunter, C. J. and Levenston, M. E., 2002. The influence of repair tissue maturation on the response to oscillatory compression in a cartilage defect repair model. Biorheology 39(12): 79-88.

Kelly, T.-A. N., Ng, K. W., Wang, C. C. B., Ateshian, G. A. and Hung, C. T., 2006. Spatial and temporal development of chondrocyte-seeded agarose constructs in freeswelling and dynamically loaded cultures. Journal of Biomechanics 39(8): 1489-1497.

Kelly, T. A., Fisher, M. B., Oswald, E. S., Tai, T., Mauck, R. L., Ateshian, G. A. and Hung, C. T., 2008. Low-serum media and dynamic deformational loading in tissue engineering of articular cartilage. Ann Biomed Eng 36(5): 769-79. 
Kelly, T. A. N., Wang, C. C. B., Mauck, R. L., Ateshian, G. A. and Hung, C. T., 2004. Role of cell-associated matrix in the development of free-swelling and dynamically loaded chondrocyte-seeded agarose gels. Biorheology 41(3-4): 223-237.

Knight, M. M., Lee, D. A. and Bader, D. L., 1998. The influence of elaborated pericellular matrix on the deformation of isolated articular chondrocytes cultured in agarose. Biochimica et Biophysica Acta - Molecular Cell Research 1405(1-3): 67-77.

Lee, D. A. and Bader, D. L., 1997. Compressive strains at physiological frequencies influence the metabolism of chondrocytes seeded in agarose. Journal of Orthopaedic Research 15(2): 181-188.

Lee, D. A., Frean, S. P., Lees, P. and Bader, D. L., 1998. Dynamic mechanical compression influences nitric oxide production by articular chondrocytes seeded in agarose. Biochemical and Biophysical Research Communications 251(2): 580-585.

Lee, D. A., Knight, M. M., F. Bolton, J., Idowu, B. D., Kayser, M. V. and Bader, D. L., 2000. Chondrocyte deformation within compressed agarose constructs at the cellular and sub-cellular levels. Journal of Biomechanics 33(1): 81-95.

Lee, D. A., Noguchi, T., Frean, S. P., Lees, P. and Bader, D. L., 2000. The influence of mechanical loading on isolated chondrocytes seeded in agarose constructs. Biorheology 37(1-2): 149-161.

Likhitpanichkul, M., Chow, C. C., Guo, X. E. and Mow, V. C., 2006. Determination of the BPVE coefficiients for agarsoe gels at various concentrations from unconfined compression. American Society of Mechanical Engineers, Bioengineering Division (Publication) BED.

Lima, E. G., Mauck, R. L., Han, S. H., Park, S., Ng, K. W., Ateshian, G. A. and Hung, C. T., 2004. Functional tissue engineering of chondral and osteochondral constructs. Biorheology 41(3-4): 577-590.

Lum, L. and Elisseeff, J., 2003. Injectable Hydrogels for Cartilage Tissue Engineering. Topics in Tissue Engineering 2003. N. Ashammakhi and P. Ferretti, University of Oulu.

Mauck, R. L., Byers, B. A., Yuan, X. and Tuan, R. S., 2007. Regulation of cartilaginous ECM gene transcription by chondrocytes and MSCs in 3D culture in response to dynamic loading. Biomechanics and Modeling in Mechanobiology 6(1-2): 113-125.

Mauck, R. L., Hung, C. T. and Ateshian, G. A., 2003. Modeling of Neutral Solute Transport in a Dynamically Loaded Porous Permeable Gel: Implications for Articular Cartilage Biosynthesis and Tissue Engineering. Journal of Biomechanical Engineering 125(5): 602-614. 
Mauck, R. L., Nicoll, S. B., Seyhan, S. L., Ateshian, G. A. and Hung, C. T., 2003. Synergistic action of growth factors and dynamic loading for articular cartilage tissue engineering. Tissue Engineering 9(4): 597-611.

Mauck, R. L., Seyhan, S. L., Ateshian, G. A. and Hung, C. T., 2002. Influence of seeding density and dynamic deformational loading on the developing structure/function relationships of chondrocyte-seeded agarose hydrogels. Annals of Biomedical Engineering 30(8): 1046-1056.

Mauck, R. L., Soltz, M. A., Wang, C. C. B., Wong, D. D., Chao, P. H. G., Valhmu, W. B., Hung, C. T. and Ateshian, G. A., 2000. Functional tissue engineering of articular cartilage through dynamic loading of chondrocyte-seeded agarose gels. Journal of Biomechanical Engineering 122(3): 252-260.

Mauck, R. L., Wang, C. C., Oswald, E. S., Ateshian, G. A. and Hung, C. T., 2003. The role of cell seeding density and nutrient supply for articular cartilage tissue engineering with deformational loading. Osteoarthritis Cartilage 11(12): 879-90.

Mauck, R. L., Wang, C. C. B., Oswald, E. S., Ateshian, G. A. and Hung, C. T., 2003. The role of cell seeding density and nutrient supply for articular cartilage tissue engineering with deformational loading. Osteoarthritis and Cartilage 11(12): 879-890.

Mauck, R. L., Yuan, X. and Tuan, R. S., 2006. Chondrogenic differentiation and functional maturation of bovine mesenchymal stem cells in long-term agarose culture. Osteoarthritis and Cartilage 14(2): 179-189.

Miyata, S., Furukawa, K., Ushida, T. and Tateishi, T., 2005. Influence of biochemical composition on dynamic visco-elastic property of chondrocyte/agarose construct. Proceedings of the 3rd IASTED International Conference on Biomedical Engineering 2005.

Miyata, S., Furukawa, K. S., Ushida, T., Nitta, Y. and Tateishi, T., 2004. Static and dynamic mechanical properties of extracellular matrix synthesized by cultured chondrocytes. Materials Science and Engineering C 24(3): 425-429.

Mouw, J. K., Case, N. D., Guldberg, R. E., Plaas, A. H. K. and Levenston, M. E., 2005. Variations in matrix composition and GAG fine structure among scaffolds for cartilage tissue engineering. Osteoarthritis and Cartilage 13(9): 828-836.

Mow, V. C., Kuei, S. C., Lai, W. M. and Armstrong, C. G., 1980. Biphasic creep and stress relaxation of articular cartilage in compression: Theory and experiments. Journal of Biomechanical Engineering 102(1): 73-84.

Ng, K. W., Mauck, R. L., Statman, L. Y., Lin, E. Y., Ateshian, G. A. and Hung, C. T., 2006. Dynamic deformational loading results in selective application of mechanical 
stimulation in a layered, tissue-engineered cartilage construct. Biorheology 43(3-4): 497507.

Ng, K. W., Saliman, J. D., Lin, E. Y., Statman, L. Y., Kugler, L. E., Lo, S. B., Ateshian, G. A. and Hung, C. T., 2007. Culture duration modulates collagen hydrolysate-induced tissue remodeling in chondrocyte-seeded agarose hydrogels. Annals of Biomedical Engineering 35(11): 1914-1923.

Ng, K. W., Wang, C. C. B., Mauck, R. L., Kelly, T. A. N., Chahine, N. O., Costa, K. D., Ateshian, G. A. and Hung, C. T., 2005. A layered agarose approach to fabricate depthdependent inhomogeneity in chondrocyte-seeded constructs. Journal of Orthopaedic Research 23(1): 134-141.

Normand, V., Lootens, D. L., Amici, E., Plucknett, K. P. and Aymard, P., 2000. New insight into agarose gel mechanical properties. Biomacromolecules 1(4): 730-738.

Quinn, T. M., Schmid, P., Hunziker, E. B. and Grodzinsky, A. J., 2002. Proteoglycan deposition around chondrocytes in agarose culture: Construction of a physical and biological interface for mechanotransduction in cartilage. Biorheology 39(1-2): 27-37.

Rahfoth, B., Weisser, J., Sternkopf, F., Aigner, T., Von Der Mark, K. and Bräuer, R., 1998. Transplantation of allograft chondrocytes embedded in agarose gel into cartilage defects of rabbits. Osteoarthritis and Cartilage 6(1): 50-65.

Sawae, Y., Shelton, J. C., Bader, D. L. and Knight, M. M., 2004. Confocal analysis of local and cellular strains in chondrocyte-agarose constructs subjected to mechanical shear. Annals of Biomedical Engineering 32(6): 860-870.

Thorpe, S. D., Buckley, C. T., Vinardell, T., O'Brien, F. J., Campbell, V. A. and Kelly, D. J., 2008. Dynamic compression can inhibit chondrogenesis of mesenchymal stem cells. Biochem Biophys Res Commun 377(2): 458-62.

Toyoda, T., Seedhom, B. B., Kirkham, J. and Bonass, W. A., 2002. Upregulation of aggrecan and type II collagen mRNA expression in bovine chondrocytes by the application of hydrostatic pressure. Biorheology 40(1-3): 79-85.

Toyoda, T., Seedhom, B. B., Yao, J. Q., Kirkham, J., Brookes, S. and Bonass, W. A., 2003. Hydrostatic Pressure Modulates Proteoglycan Metabolism in Chondrocytes Seeded in Agarose. Arthritis and Rheumatism 48(10): 2865-2872.

Walker, E. A., Verner, A., Flannery, C. R. and Archer, C. W., 2000. Effect of compressive loading on chondrocyte differentiation in agarose cultures of chick limb-bud cells. Journal of Orthopaedic Research 18(1): 78-86. 
Weisser, J., Rahfoth, B., Timmermann, A., Aigner, T., Bräuer, R. and Von der Mark, K., 2001. Role of growth factors in rabbit articular cartilage repair by chondrocytes in agarose. Osteoarthritis and Cartilage 9(SUPPL. A): S48-S54.

Xu, X., Urban, J. P. G., Tirlapur, U., Wu, M. H. and Cui, Z., 2006. Influence of perfusion on metabolism and matrix production by bovine articular chondrocytes in hydrogel scaffolds. Biotechnology and Bioengineering 93(6): 1103-1111. 


\section{FIGURE LEGENDS}

Figure 1. Cooling rates used when fabricating agarose hydrogels. Gels are cooled to approximately $37{ }^{\circ} \mathrm{C}$, and then either rapidly cooled or slowly cooled to $20^{\circ} \mathrm{C}$.

Figure 2. Ramp and hold strain regime applied to investigate the linearity of the equilibrium modulus of agarose hydrogels, with corresponding stress values.

Figure 3. (a) Stress-strain curves for agarose gels subjected to ramp compression and tension at $0.5 \% / \mathrm{sec}$, from which the ramp modulus was determined. Negative values on the $\mathrm{x}$-axis indicate compressive strains. (b) Equilibrium stress-strain data determined from a series of 10 ramp and holds tests applied in either tension or compression. Each data point represents the equilibrium stress following relaxation at the corresponding strain value.

Figure 4. Influence of gel concentration and mechanical testing temperature for (a) $2 \%$, (b) $4 \%$ and (c) $6 \%$ agarose hydrogels on the equilibrium modulus and dynamic modulus at $0.1 \mathrm{~Hz}, 1 \mathrm{~Hz}$ and $5 \mathrm{~Hz}$. Agarose hydrogels were tested at either room temperature (RT) or at $37^{\circ} \mathrm{C}$ as described in the methods section. Samples tested at room temperature had either been kept at room temperature prior to testing (RT-RT), or had been placed overnight in an incubator at $37^{\circ} \mathrm{C}\left(37^{\circ} \mathrm{C}-\mathrm{RT}\right) . *$ indicates significance $(\mathrm{p}<0.05)$, ** $(\mathrm{p}<0.01), * * *(\mathrm{p}<0.001)$. 
Figure 5. Influence of initial cell seeding density on (a) equilibrium modulus and (b) $1 \mathrm{~Hz}$ dynamic modulus of chondrocyte seeded agarose hydrogels. Samples were fabricated by mixing the cell suspension with $4 \%$ agarose. The cell suspension was made by either adding culture media to the cell pellet to obtain a final volume equal to that of the agarose (Method A), or by adding a volume of culture media equal to that of the agarose to the pellet (Method B). The volume occupied by the cell pellet increases with increasing cell concentration. For method B, this implies that the effective cell seeding density is actually slightly lower than required (based on the total volume), while for method A the effective agarose concentration may actually increase with increasing cell concentration. $*$ indicates significance $(\mathrm{p}<0.05), * *(\mathrm{p}<0.001)$.

Figure 6. Batch-Batch variation analysis of $2 \%$ agarose hydrogels fabricated, maintained and tested at room temperature $(\mathrm{RT}) . *$ indicates significance compared to batches A and $\mathrm{B}(\mathrm{p}<0.05), * *$ compared to batches $\mathrm{A}, \mathrm{B}$ and $\mathrm{E}(\mathrm{p}<0.05), * * *$ compared to batch $\mathrm{B}$ $(p<0.05)$ and + compared to batches B and $E(p<0.05)$. 


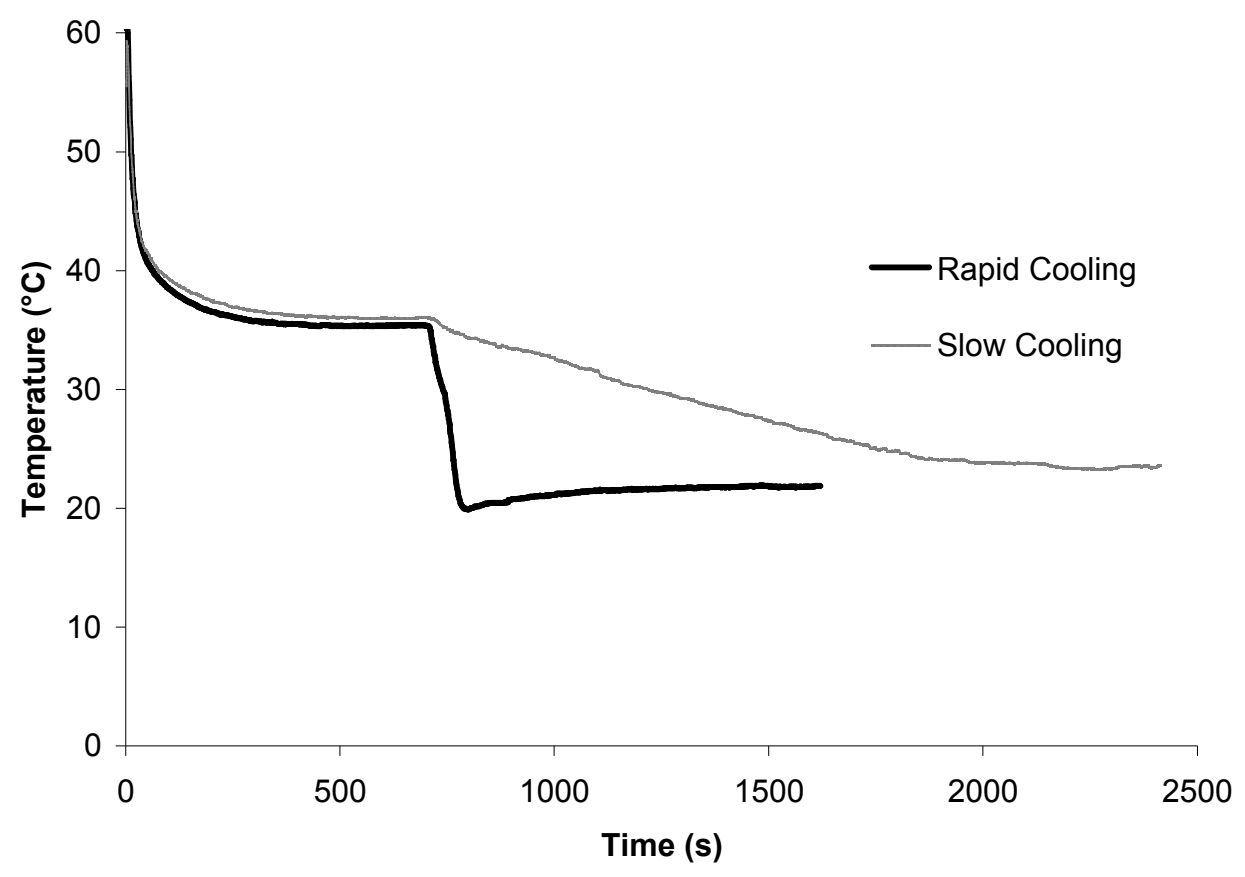

Fig. 1.

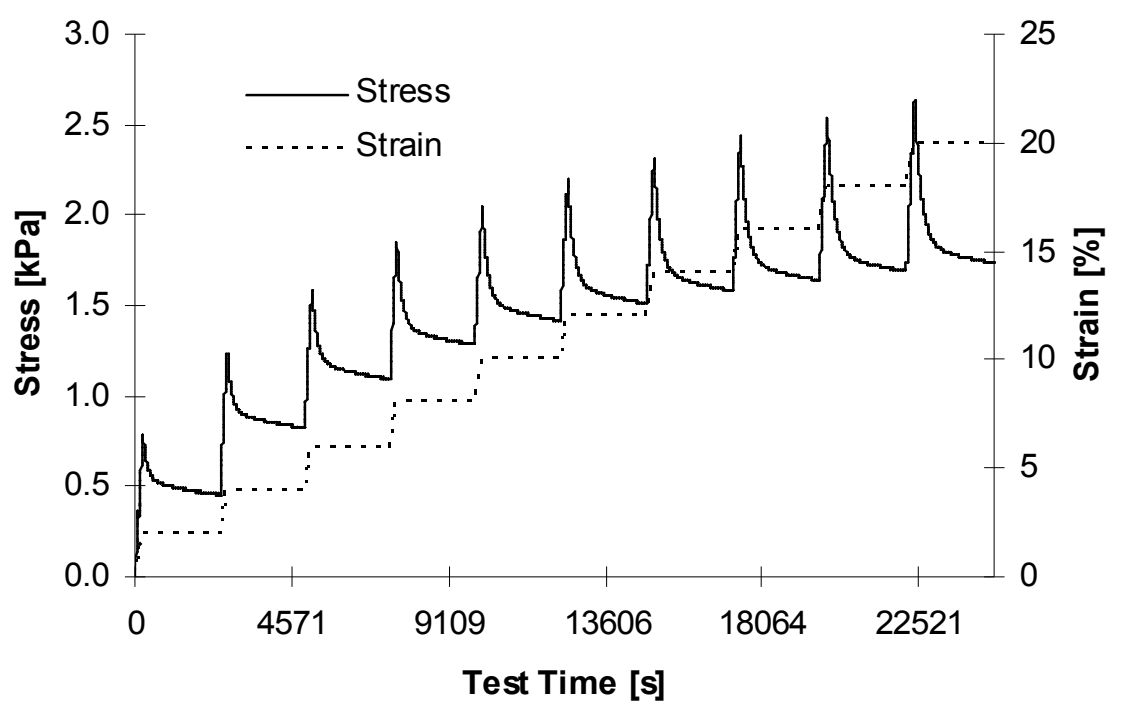

Fig. 2. 


\section{Ramp Modulus $(0.5 \% / \mathrm{sec})$}

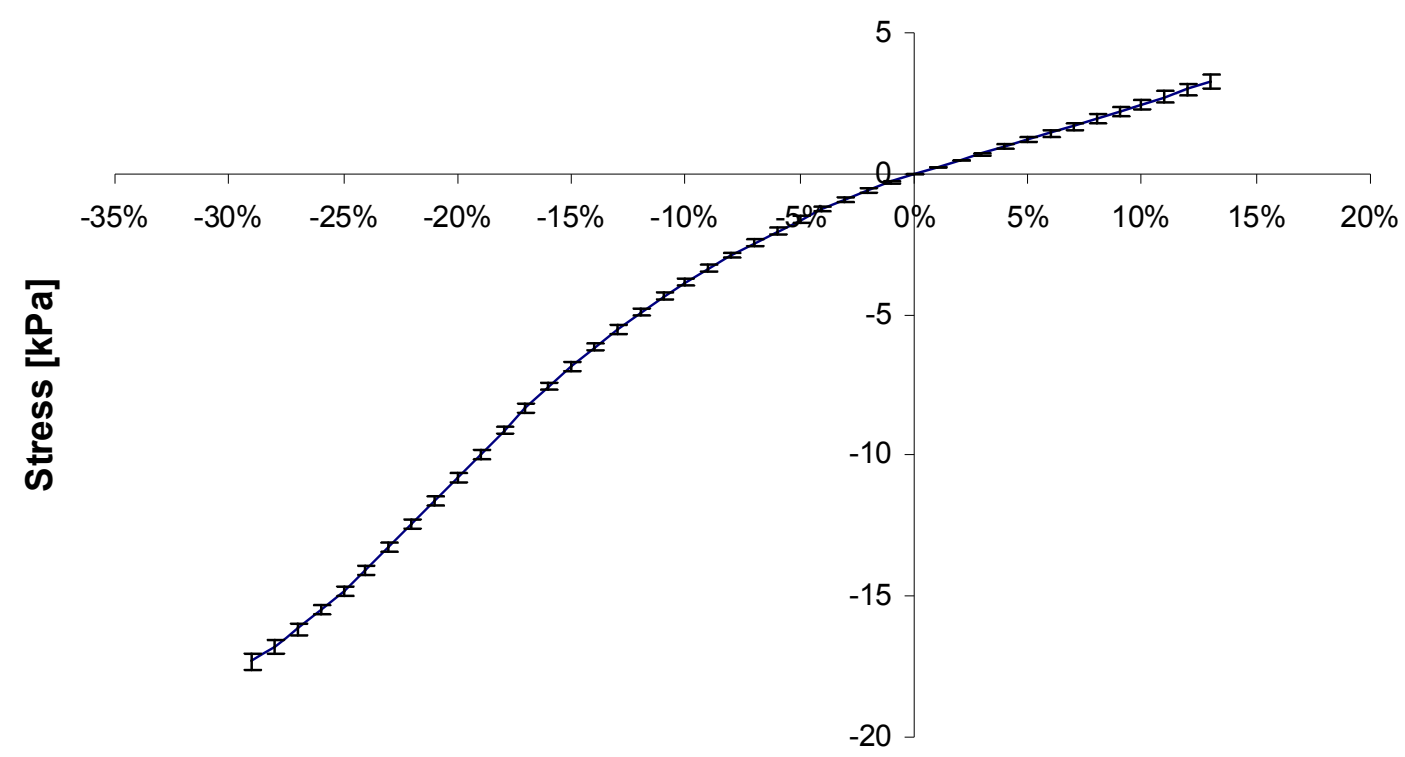

Strain

(a)

Equilibrium modulus

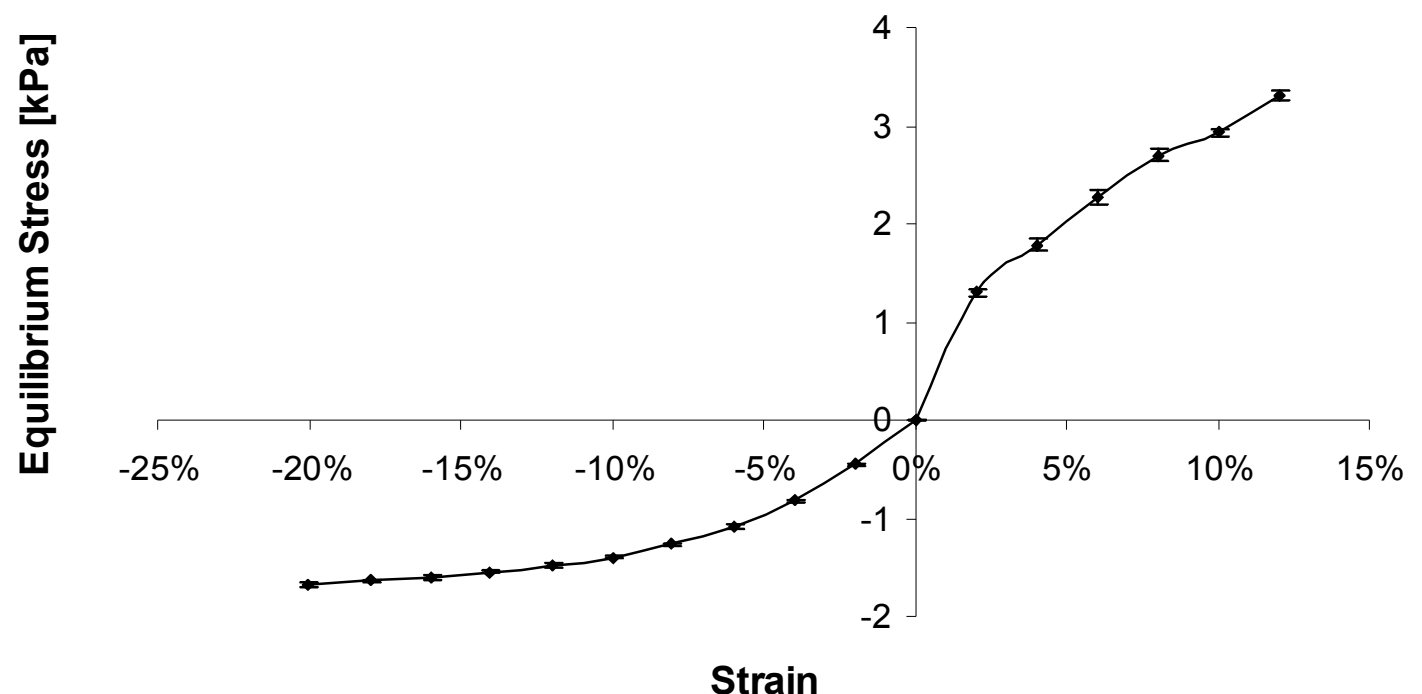

(b)

Fig. 3. 


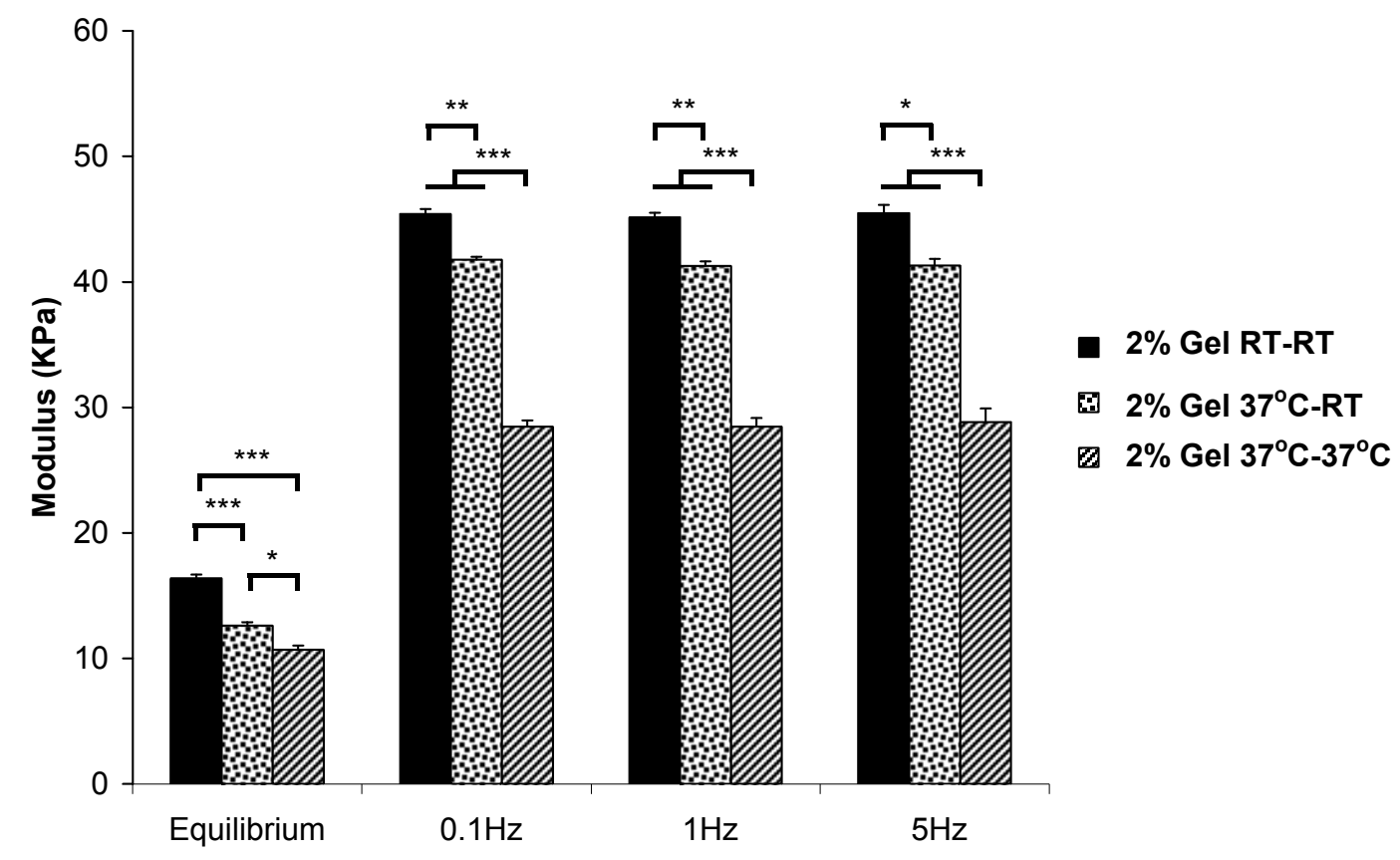

(a)

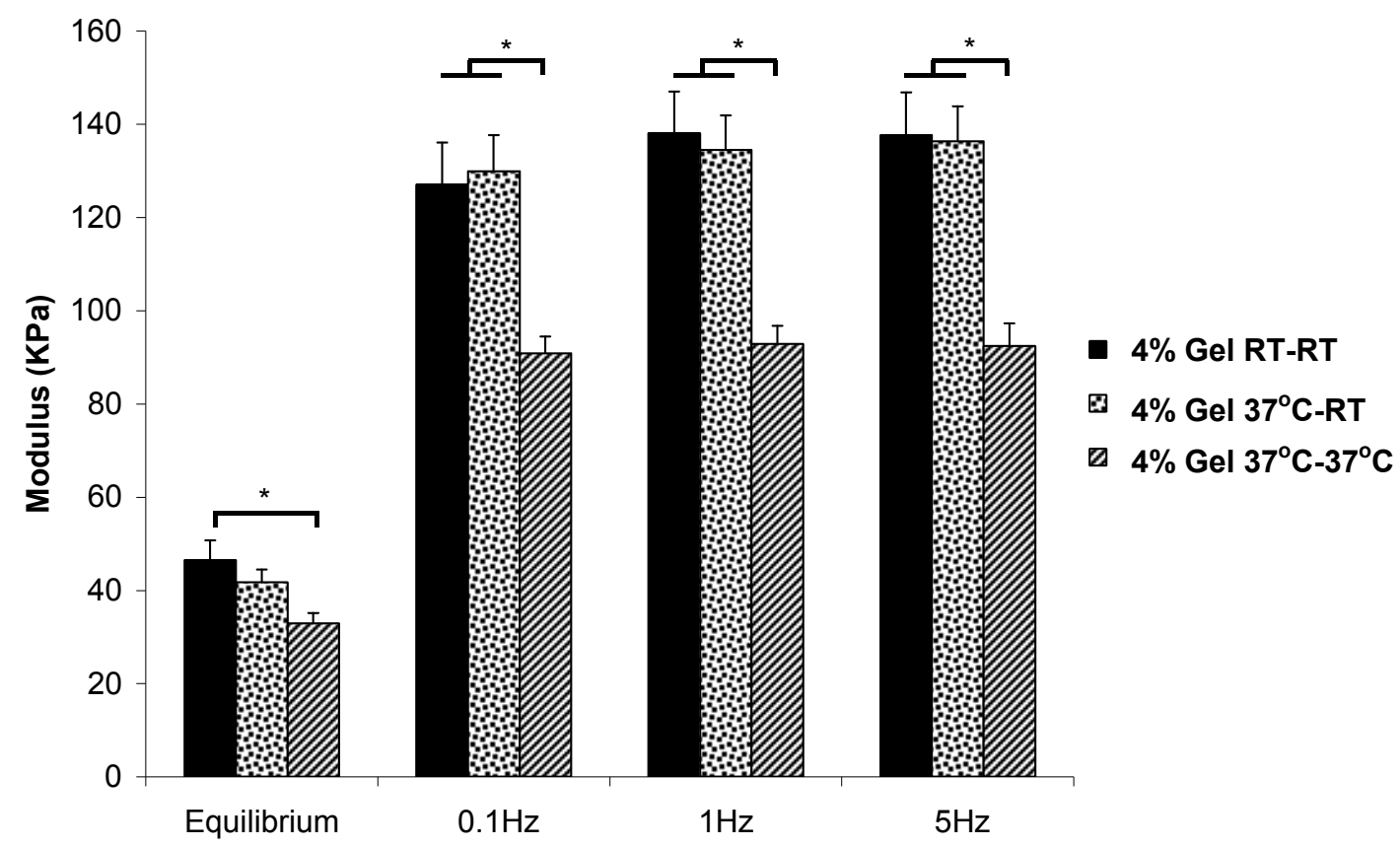

(b) 


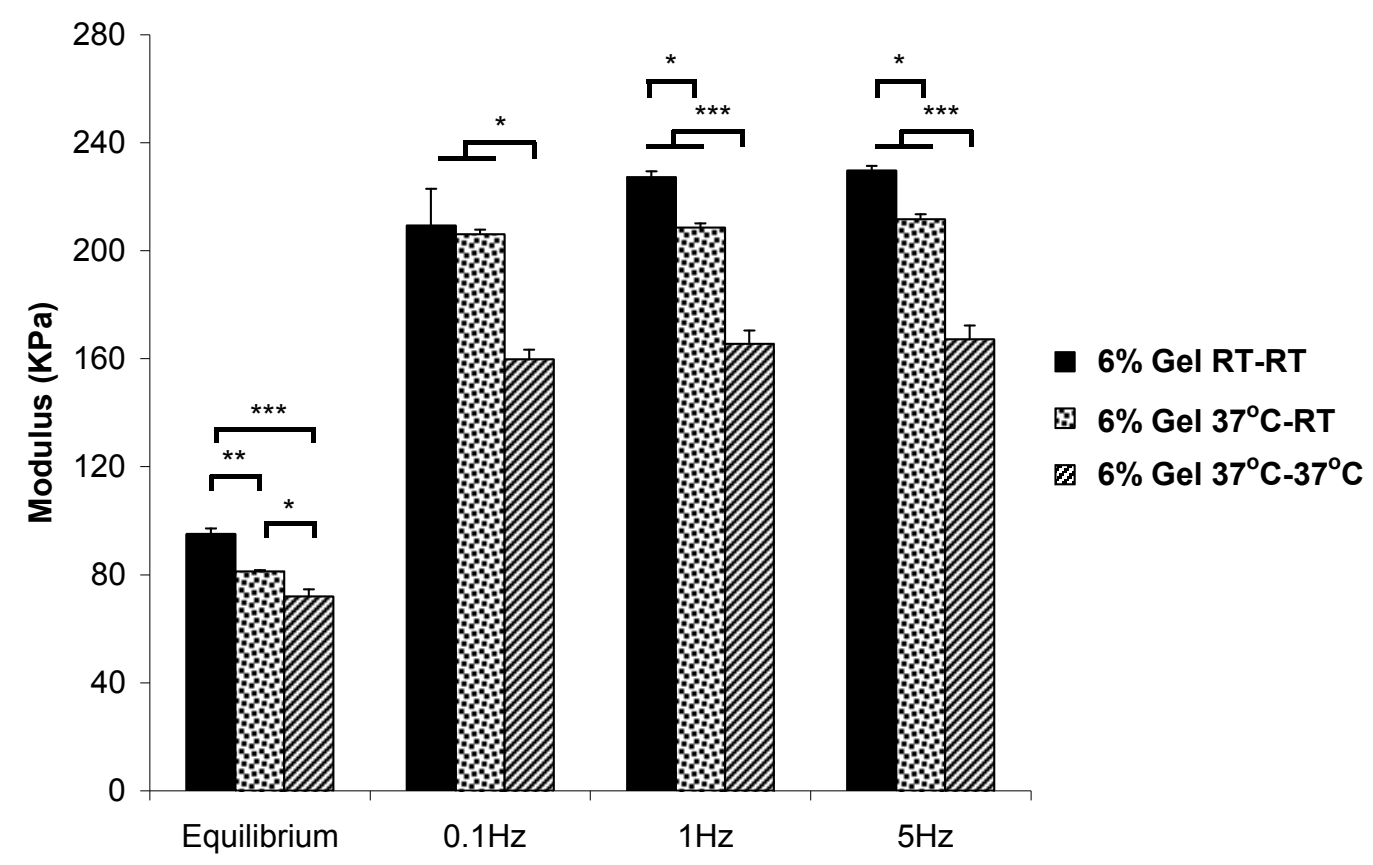

(c)

Fig. 4. 


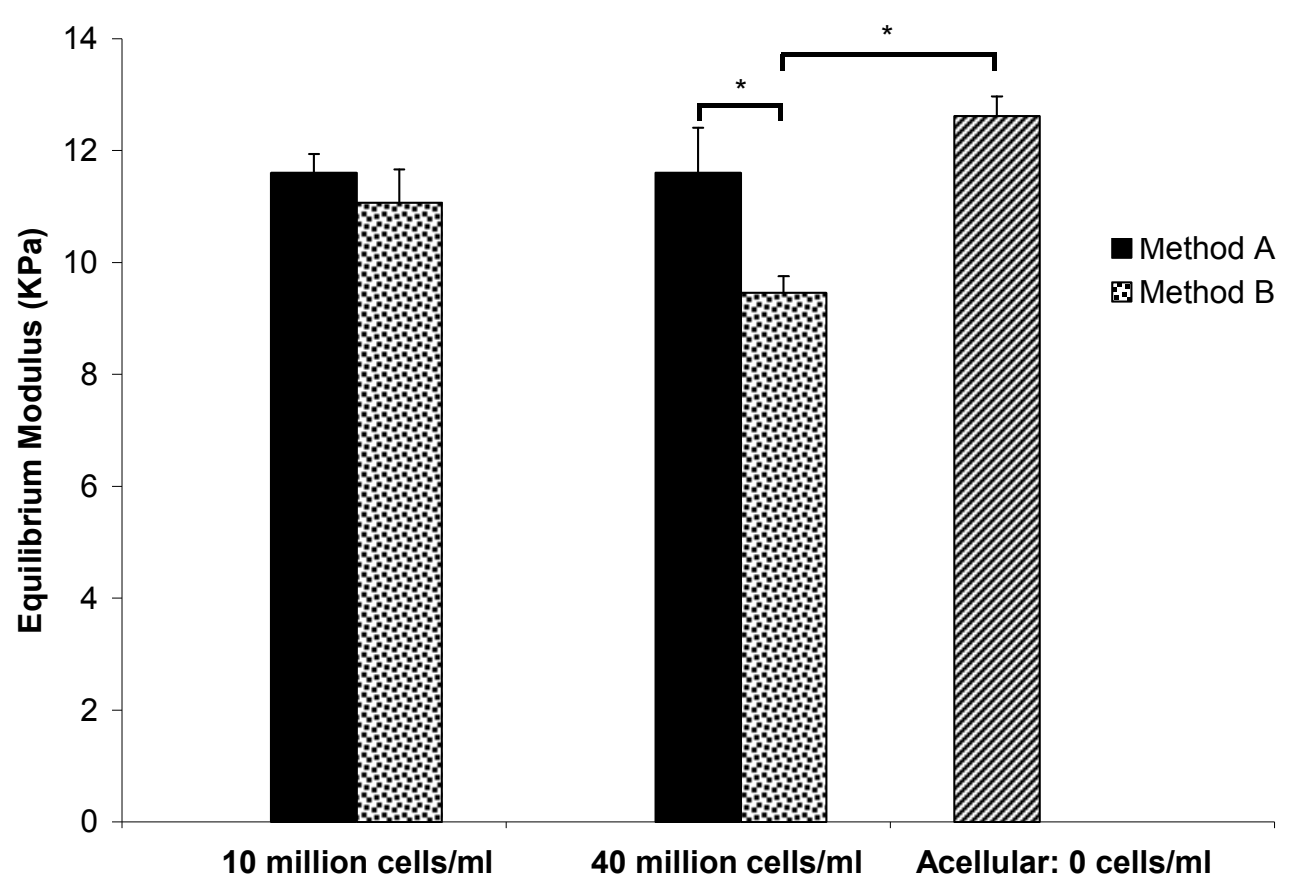

(a)

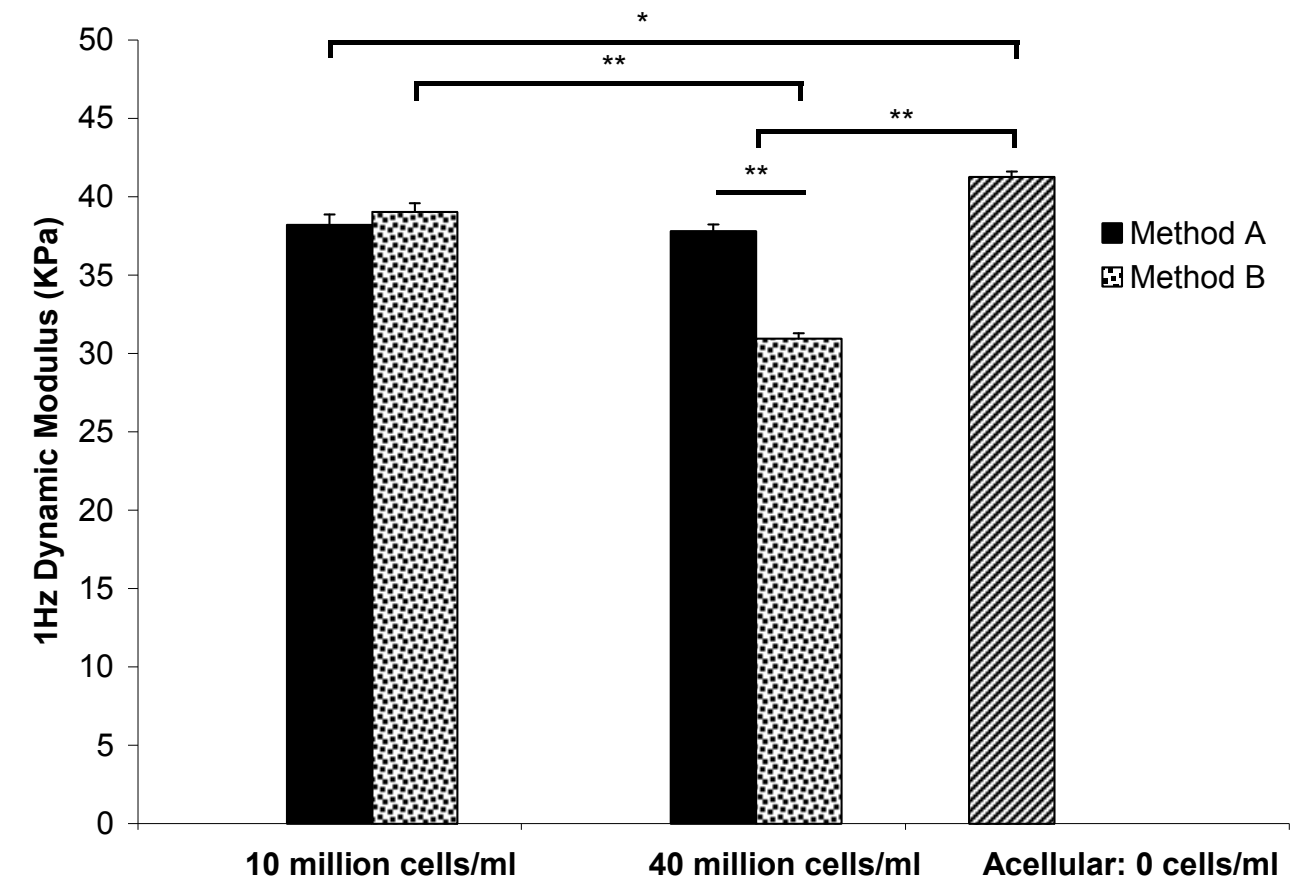

(b)

Fig. 5. 


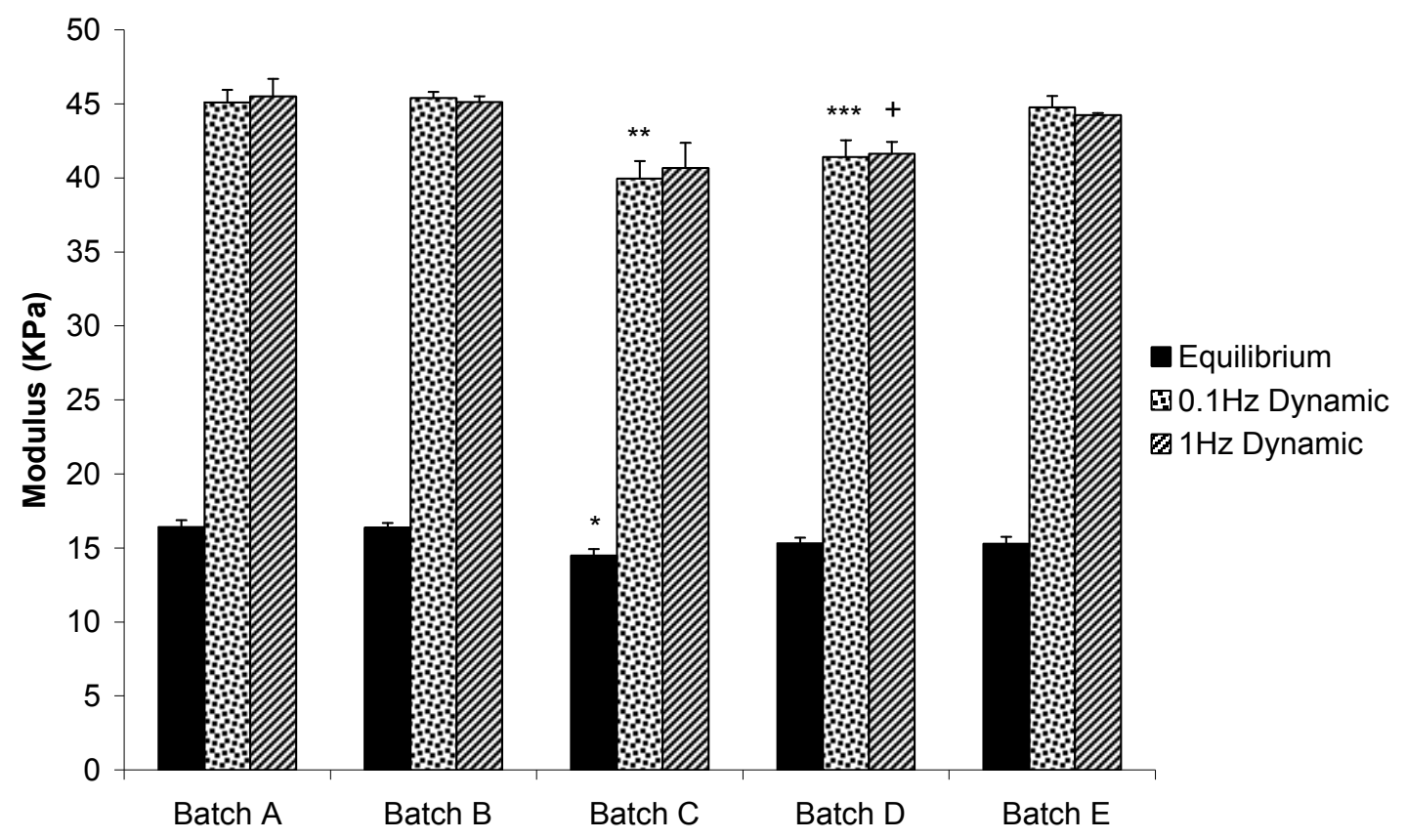

Fig. 6. 